\title{
POPULATION CYTOLOGY OF THE GENUS PHAULACRIDIUM
}

\author{
M. WESTERMAN \\ Department of Genetics and Human Variation, La Trobe University, Melbourne
}

Received 4.iii.74

\begin{abstract}
SUMMARY
Ten of the 27 populations of Phaulacridium marginale collected from South Island, New Zealand, during the 1973 meiotic season were polymorphic for extra heterochromatin. This was present either as B chromosomes or as supernumerary segments on the shortest autosomes. In some populations both polymorphisms were present simultaneously, sometimes at high frequencies. Three different types of B chromosome were seen; large telocentric, small telocentric and small metacentric isochromosomes though only one type was seen in any one population. Segments on the telocentric $S_{9}$ and $S_{10}$ chromosomes were located distally. On the $S_{11}$ chromosome, however, the extra segment was present as a short arm, thus making the chromosome submetacentric. This latter situation is similar to that in the related species Ph. vittatum. The frequency of B's in the OM population appeared to be stable over years and there was no indication of any meiotic "drive " or " drag " in the males. The frequency of occurrence of $B$ chromosomes in a population correlated negatively with annual rainfall (low B frequencies in regions of high rainfall). Neither type of extra heterochromatin had any significant effect on either mean cell chiasma frequency or on log variance of this metric. Possible synergism between B's and segments is discussed from the preliminary analysis of the OM population. The probable origins and age of the polymorphisms are discussed in detail.
\end{abstract}

\section{INTRODUGTION}

Populations of the brachypterous New Zealand grasshopper Phaulacridium marginale have been shown to be polymorphic for both $\mathrm{B}$ chromosomes and extra segments on the three smallest autosomes (Martin, 1970; Westerman and Fontana, 1973; Westerman, 1974). It is known that such polymorphisms for supernumerary heterochromatic material are widespread in both plants and animals (see Battaglia, 1964; White, 1973). Although much has been learned of the probable role of this extra heterochromatin in natural populations (John and Hewitt, 1965a, $b$; Westerman, 1969, 1970; Puteyevsky and Zohary, 1970; Shaw, 1971; Zarchi et al., 1972), to date no detailed studies have been done on species in which both supernumerary chromosomes and segments co-exist in the same individuals.

Westerman and Fontana (loc. cit.) reported that in at least one population of the grasshopper $P$. marginale, B chromosomes and supernumerary segments existed together at a very high frequency- 6 out of 17 individuals collected at Omarama contained both. This contrasts with the only previous report of simultaneous presence of B's and extra segments where only 2.0 per cent of individuals in one population of Camnulla pellucida carried both (Nur, 1969). Detailed studies on such populations as these should reveal any synergisms between the two types of extra heterochromatin. The present paper describes the types of polymorphisms present in popula- 
tions of $P h$. marginale and their distribution in South Island, New Zealand, together with a preliminary analysis of the Omarama population.

\section{Materials and methods}

Since $P h$. marginale is common in New Zealand in open grasslands below $100 \mathrm{~m}$, young adult males were collected from a number of sites throughout South Island during the 1973 meiotic season (see Westerman, 1974, for details). Ten of the 27 populations sampled were found to be polymorphic for $\mathrm{B}$ chromosomes and/or supernumerary segments.

\section{Results}

(i) The $B$ chromosomes

B chromosomes would appear to be widespread in $P h$. marginale as six of the populations sampled from South Island had B's present in from 5 to 50 per cent of males (see table 1). Martin (1970) has reported the presence

TABLE 1

$B$ chromosome frequencies in six South Island populations of $\mathrm{Ph}$. marginale. $\left(q_{B}=\right.$ frequency of $B$ 's in a population)

\begin{tabular}{|c|c|c|c|c|c|c|c|}
\hline \multirow{3}{*}{ Population* } & \multicolumn{5}{|c|}{ Number of individuals } & \multirow{3}{*}{$q_{B}$} & \multirow{3}{*}{$q_{B}$ in angles } \\
\hline & \multirow[t]{2}{*}{ sampled } & \multicolumn{4}{|c|}{ per class B } & & \\
\hline & & $\mathrm{OB}$ & $1 \mathrm{~B}$ & $2 \mathrm{~B}$ & $3 B$ & & \\
\hline TP & 19 & 17 & 2 & - & - & $0 \cdot 2527$ & $13 \cdot 31$ \\
\hline LC & 22 & 18 & 4 & - & - & 0.0910 & $17 \cdot 56$ \\
\hline$\overline{\mathrm{SU}}$ & 6 & 3 & 1 & 2 & - & 0.4167 & $40 \cdot 22$ \\
\hline AW & 21 & 15 & 5 & 1 & - & $0 \cdot 1667$ & $24 \cdot 09$ \\
\hline AO & 19 & 18 & 1 & - & - & 0.0264 & $9 \cdot 36$ \\
\hline \multirow[t]{2}{*}{ OM (1973) } & 27 & 14 & 8 & 5 & 一 & 0.3333 & $35 \cdot 27$ \\
\hline & & & & \multicolumn{4}{|c|}{$\begin{aligned} \chi_{5}^{2} & =2 \cdot 2953 \\
\mathrm{P} & =>0 \cdot 20\end{aligned}$} \\
\hline OM (1972) & 17 & 10 & 3 & 2 & 2 & 0.2549 & $30 \cdot 26$ \\
\hline $\mathrm{OM}(1969) \dagger$ & 14 & 7 & 3 & 4 & - & 0.3928 & $38 \cdot 82$ \\
\hline
\end{tabular}

of B chromosomes in three of eight samples taken from North Island with frequencies ranging from 6 to 33 per cent. To date, three morphologically different types of B chromosome have been found although only one type is found in any one population. These range in size from a large telocentric element roughly equal in size to the $\mathrm{X}$ chromosomes (also telocentric) (see plate I, $a$ and $b$ and plate II, $a$ and $b$ ), to a smaller telocentric chromosome approximately one-third the size of the $\mathrm{X}$ (plate $\mathrm{I}, \mathrm{c}$ and $\mathrm{d}$ ) and a small metacentric isochromosome (see plate $I$, e and $\mathrm{f}$ ). It seems possible that the long telocentric B chromosome is the basic type from which the others can be secondarily derived by loss of material and subsequent misdivision of the centromere to give an isochromosome (see discussion below).

All three types of B chromosome appear to be mitotically stable in $P h$. marginale males, at least in the germ line, as the same number of $\mathrm{B}$ 

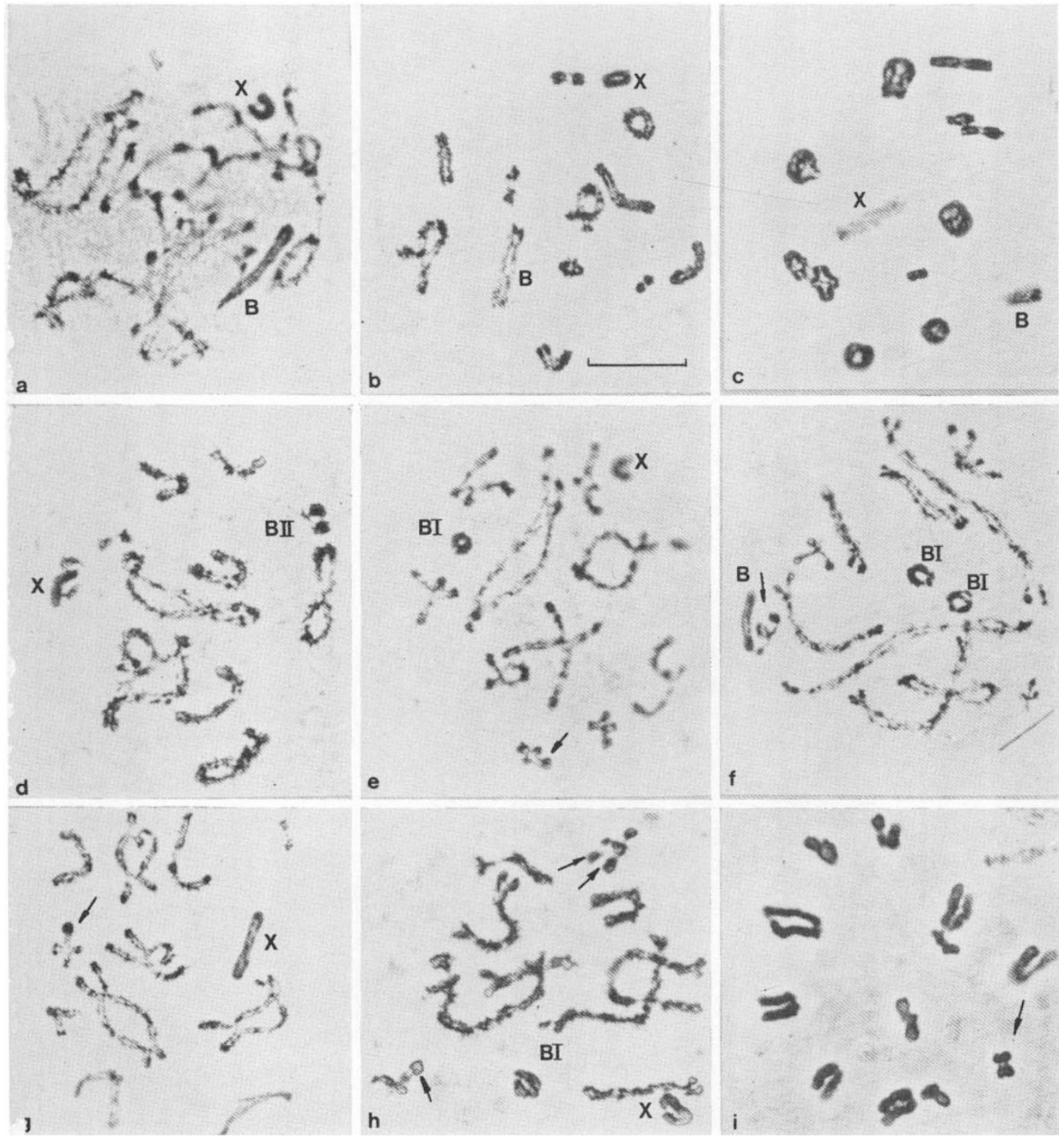

Plate I

The B-chromosome types and supernumerary segments encountered in Ph. marginale. Large telocentric B chromosome at early diplotene (a), diakinesis (b).

Small teleocentric B chromosome at metaphase I (c), bivalent at early diplotene (d).

Metacentric isochromosome forming a ring univalent (e), 2-ring univalents ( $f$ ).

Supernumerary segments present as heteromorphic $S_{10}(g)$, homomorphic $S_{9}$, heteromorphic $\mathrm{S}_{10}(\mathrm{~h})$, hcteromorphic $\mathrm{S}_{11}(\mathrm{i})$.

$($ Line scale $=10 \mu \mathrm{m})$ 


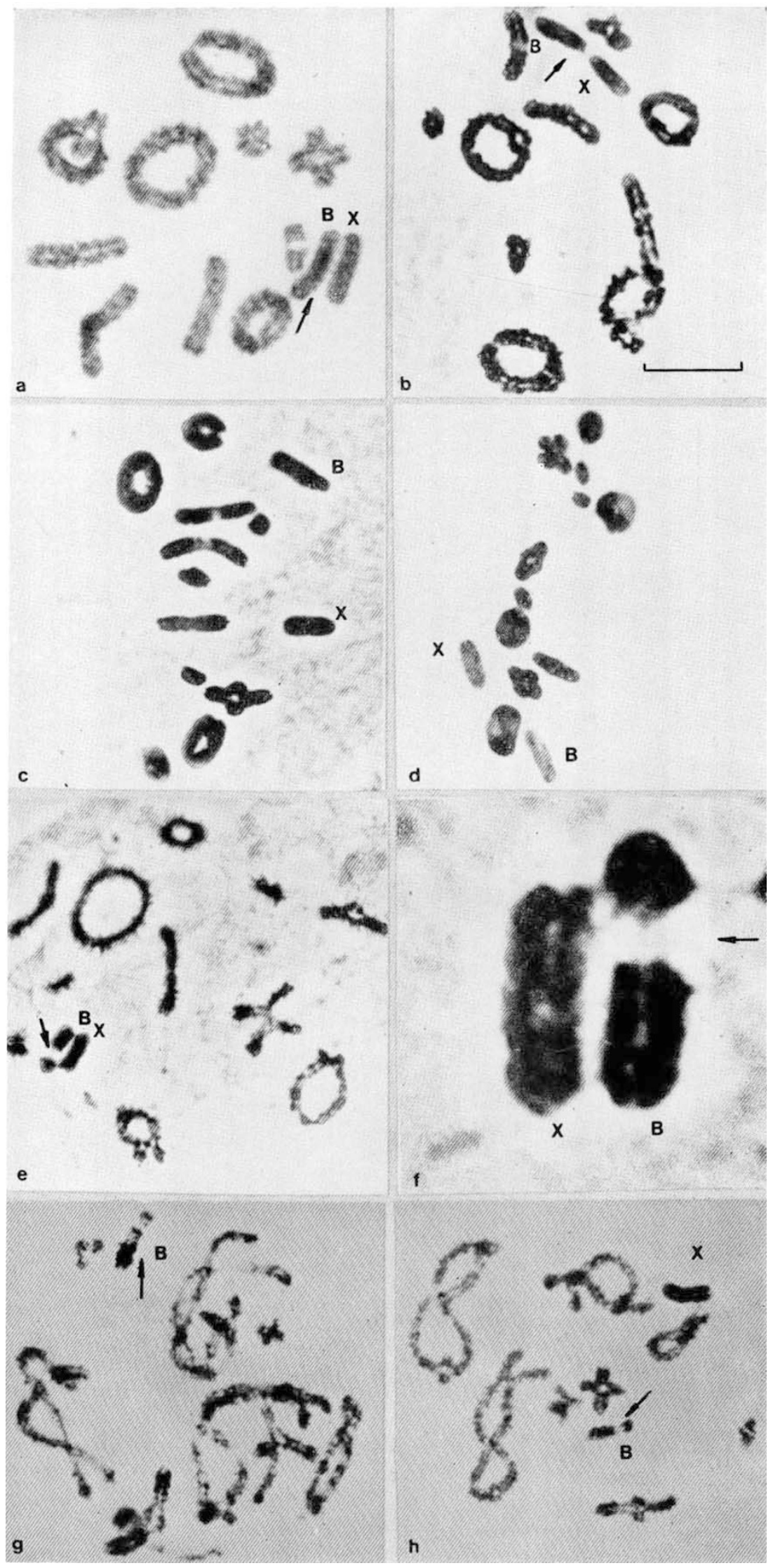




\section{Platc II}

Meiotic behaviour of the B chromosome.

$\mathrm{a}, \mathrm{b}$ Diakinesis cells showing pairing behaviour of $\mathrm{X}$ and $\mathrm{B}$. $\mathrm{a}$, side by side (note cross connections); $\mathrm{b}$, end to end.

c, d Metaphase I cells showing X and B segregating to c, same pole; d, to opposite poles.

$\mathrm{e}, \mathrm{f}, \mathrm{g}, \mathrm{h}$ Euchromatic regions on the B chromosomes of Ph. marginale $(\mathrm{e}, \mathrm{f})$, and Chorthippus parallelus $(\mathrm{g}, \mathrm{h})$.

$$
(\text { Line scale }=10 \mu \mathrm{m})
$$


chromosomes were present in all spermatocytes of an individual. This is true also of individuals carrying two and three B's. In the one population (OM) from which more than one sample has been obtained, the frequency of B chromosomes is also stable from year to year (see table 1), as are the B's in Ph. vittatum (Jackson and Cheung, 1967) and in M. maculatus (Hewitt and John, 1967).

Despite the similarities between the $\mathrm{X}$ and the long telocentric $\mathrm{B}$ chromosomes there are some differences in their coiling behaviour in meiotic prophase. Both elements appear as deeply staining masses during leptotene, zygotene and early pachytene. Subsequently the chromosomes are seen as separate entities which remain positively heteropycnotic with respect to the autosomes at diplotene (plate I, a, d and e), become weakly negatively heteropycnotic at Metaphase I (see plate I, c; plate II, d) and isopycnotic at later stages. The coiling cycles of the $\mathrm{B}$ and $\mathrm{X}$ are not synchronous, however, as the $\mathrm{B}$ chromosome is relatively less condensed than the $\mathrm{X}$ at diplotene (plate I, a) and diakinesis (plate I, b).

Not all B chromosomes were uniform along their length in their coiling and staining. Thus in one individual from the $\mathrm{SU}$ and $\mathrm{LC}$ populations a region of euchromatin was observed close to the centromere and lying between a small proximal and a much larger distal block of heterochromatin (see plate II, e and f). Similar euchromatic regions have also been noted in this species by Martin (1970) in individuals from Wellington (see her fig. 2la) and by Hewitt and John (1972) in one Podisma pedestris individual taken from Neuenkirken. Since the pattern of coiling of the B chromosome may differ both between individuals within a population as well as between cells of the same individual (see Martin, 1970), it would seem unnecessary to argue for an independent origin of B's with and without euchromatic regions in the same species (see Hewitt and John, 1972). Such regions of different coiling cycles within B chromosomes are perhaps widespread in the Orthoptera (see fig. 2c and 2d) and may reflect presence and occasional activity of secondary constrictions known to be present in many grasshopper $\mathrm{X}$ chromosomes from which many B's are probably derived (see below).

Not only were the coiling cycles of the $\mathrm{X}$ and $\mathrm{B}$ chromosomes similar in $P h$. marginale, but they were frequently seen lying side by side (plate II, a) or end-to-end (plate II, b) at diplotene-diakinesis, often with fibrilar elements connecting the two. Such associations were never observed to be chiasmate and the $\mathrm{X}$ and $\mathrm{B}$ invariably separated from each other before Metaphase I (cf. Jackson and Cheung, 1967; Fontana and Vickery, 1973).

When two or more B's were present in the same cell they could, and often did, pair and form chiasmata, giving rise to a regular bivalent (see plate I, d). Although the metacentric isochromosomes seen in the OM population were capable of pairing to form bivalents, they by no means always did so. Usually pairing and chiasma formation was between the two homologous arms of one chromosome giving rise to ring univalents (plate, I, e and $\mathbf{f}$ ). Such behaviour probably simply reflects the closer proximity of the fully homologous arms of the isochromosomes for pairing and crossing over.

At anaphase I, all B-chromosome univalents behaved in a similar way. Whether rings or rods they always moved undivided to one pole or the other, the direction of movement being completely at random with respect to the $\mathrm{X}$ chromosome or to other univalent B's (see table 2 and plate II, $\mathrm{c}$ and $\mathrm{d}$ ). Thus in $P h$. marginale there is no evidence for any form of meiotic drive or 


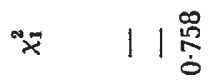
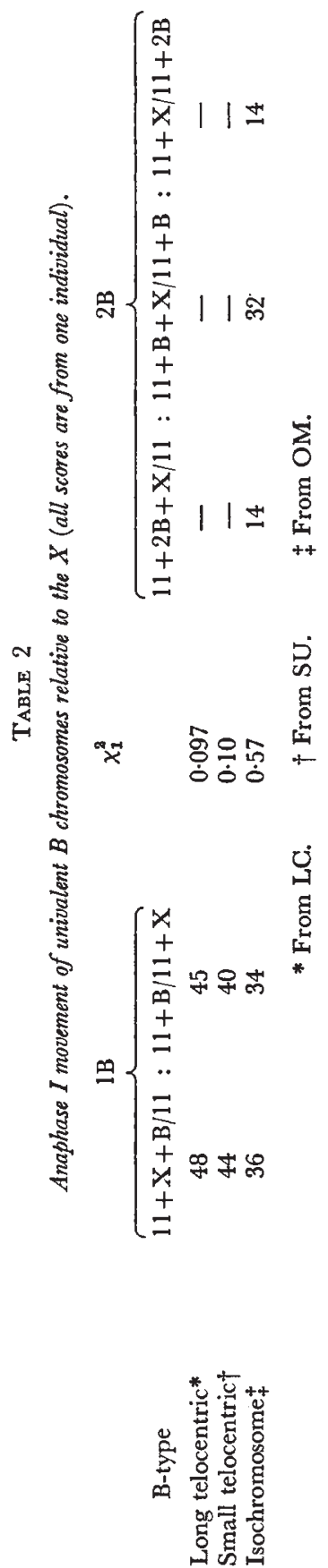
segregation distortion of the B chromosomes, at least not prior to spermiogenesis. This is also true of some Australian mainland populations of the closely related species $P h$. vittatum (Rowe and Westerman, 1974; John and Freeman, 1974).

Since it is known in some species that the frequency of B chromosomes in a population is related to certain environmental parameters (Hewitt and John, 1970; Hewitt and Ruscoe, 1971), a series of multiple regression analyses were run using various climatic factors as independent variables (see Westerman, 1974, for details). Only two of the parameters tested appeared to be significantly correlated with the B frequency (in angles) of a population. These were annual rainfall $(b=-6.7319)$ and July rainfall $(b=49 \cdot 2903)$. The difference in sign, i.e. low B frequency correlating with high annual rainfall but with low July (winter) rainfall, probably reflects the different requirements of this organism at different stages of development.

\section{(ii) The supernumerary segments}

Seven of the South Island populations of $P h$. marginale were polymorphic for supernumerary heterochromatic segments. As with many other Acridid species, these segments were found only on the shorter members of the chromosome complement-the $\mathrm{S}_{9}, \mathrm{~S}_{10}$ and $\mathrm{S}_{11}$ chromosomes (see plate $I, g, h$ and $i)$. In the case of the $S_{9}$ and $S_{10}$ bivalents the extra segment consisted of a large block of heterochromatic material located on the distal end of the chromosome which increased the size of the chromosome by some 30 per cent (see also Nur, 1961 ; Hewitt and John, 1968; Westerman, 1970; Shaw, 1971). Heteromorphic $S_{9}$ and $S_{10}$ bivalents invariably divided equationally at anaphase I and reductionally at anaphase II.

The segments on the $S_{11}$ chromosome differed from the above in being attached to the centric end, thus making the $S_{11}$ into a sub-metacentric chromosome (type D, figure 9-11, White, 1973) (see plate I, i). This is similar to the situation in the related species Ph. vittatum (Rowe and Westerman, 1974), in Oedaleonotus enigma (Hewitt and Schroeter, 1969) and in Onortoicetes terminifera (Hewitt and John, 1971). The heteromorphic $\mathrm{S}_{11}$ bivalent always divided reductionally at anaphase $I$ and equationally at anaphase II (plate I, i). The direction of segregation of the half-bivalent carrying the extra segment was at random with respect to both the $\mathrm{X}$ chromosome and any B's present. Despite being heterochromatic, the extra segment on the three short chromosomes were never seen associated either with each other, with the B's, or with the heterochromatic X chromosome.

A comparison of the karyotype frequencies seen in the seven populations with the expectations based on Hardy-Weinberg distributions is shown in table 3. In no case did the observed frequencies differ from those expected. Since the $S_{11}$ polymorphism was present in six populations a heterogeneity $\chi^{2}$-test was carried out to see if the populations differed in the frequency of segments. The results in table 4 show that the six populations do not differ significantly. From the limited data available it would seem that in the OM population the karyotype frequencies are stable over years (table 3 ).

Regression analyses carried out to ascertain the relationship between segment frequency of the population (in angles) and various climatic 


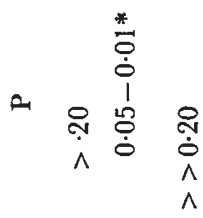

$\ddot{\square}-\longrightarrow$ n

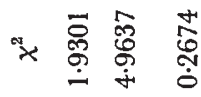

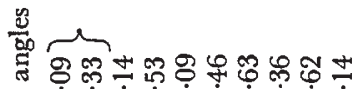

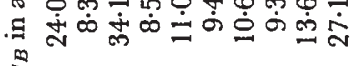

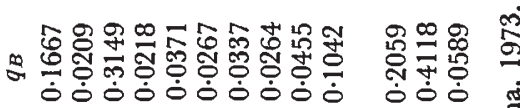

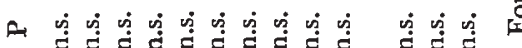

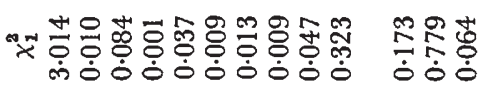

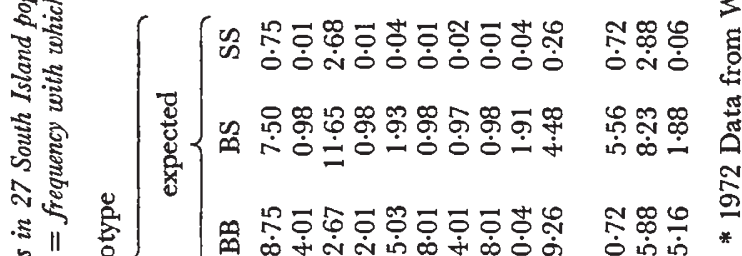
ค 
parameters again gave only two significant correlations. Once again these were annual rainfall $(b=-8 \cdot 22)$ and July (winter) rainfall $(b=58 \cdot 74)$. Although in this case both $b$ values were only of borderline significance $(P=0.03$ and $P=0.04$ respectively), they do have the same sign as with the B's.

TABLE 4

Heterogeneity $\chi^{2}$-test on the $S_{11}$ data in table 3

$\begin{array}{lccc}\quad \text { Item } & \text { d.f. } & \text { Value } & \mathbf{P} \\ \text { Deviation } \chi^{2} & 1 & 0 \cdot 035 & \text { n.s. } \\ \text { Heterogeneity } \chi^{2} & 5 & 0.133 & \text { n.s. }\end{array}$

(iii) The effect of the extra heterochromatin on chiasma frequency

In some organisms the presence of supernumerary heterochromatin has a pronounced effect on either or both the mean number of chiasmata per cell (John and Hewitt, 1965a, b; Hewitt and John, 1968; Westerman, 1969;

TABLE 5

Analysis of variance of effect of $B$ chromosomes or extra segments on mean cell chiasma frequency

Item

B $v$ non-B SS

Within groups SS

B $v$ non-B SS

Within groups SS

B $v$ non-B SS

Within groups SS

Segs $v$ no segs SS

Within groups SS

Segs $v$ no segs SS

Within groups SS

Segs $v$ no segs SS

Within groups SS

Segs $v$ no segs SS

Within groups SS d.f.

1

20

1

4

1

19

1

13

1

27

1

20

1

22
M.S.

F

$\mathbf{P}$

(a) Lindis Creek

0.04879
1.3323

$0.3662>0.20$

(b) Sumner

$1 \cdot 2149$

$9 \cdot 3934$

(c) Awatere

1.9431

$0 \cdot 4507$

(d) Lake Ohau

3.6802

$1 \cdot 1383$

(e) Lake Pukaki

$0 \cdot 2096$

$1 \cdot 6937$

$<1 \quad>0 \cdot 20$

(f) Ariki Junction

0.2041

$1 \cdot 6345$

(g) Skippers Saddle

$0.2632 \quad<1 \quad>0.20$

Zécevič and Paunovič, 1969; Zarchi et al., 1972) and on between cell variance of chiasma frequency (Jones and Rees, 1967). When populations in which either B chromosomes or segments were present alone were analysed separately, in no case did the extra heterochromatin appear to have any effect on either mean chiasma frequency or log variance (see tables 5 and 6), and neither were any consistent trends (see table 7). 
Three populations ( $\mathrm{TP}, \mathrm{AO}$ and $\mathrm{OM}$ ) were simultaneously polymorphic for both $\mathrm{B}$ chromosomes and extra segments though in only one case (OM)

TABle 6

Analysis of variance of effect of $B$ chromosomes or extra segments on between cell log variance

Item

B $v$ non-B SS

Within groups SS

B $v$ non-B SS

Within groups SS

B $v$ non-B SS

Within groups SS

Segs $v$ no segs SS

Within groups SS

Segs $v$ no segs SS

Within groups SS

Segs $v$ no segs SS

Within groups SS

Segs $v$ no segs SS

Within groups SS d.f.

1

20

1

19

1

19

1

13

1

21

1

20

1

22
M.S. F

$\mathrm{P}$

(a) Lindis Cree

$0.0001<1>0.20$ n.s.

0.0505

(b) Sumner

0.00034

0.0709

$<1 \quad>0.20$ n.s.

(c) Awatere

$0.1441 \quad 2.0324>0 \cdot 10$ n.s.

(d) Lake Ohau

0.2619

$0 \cdot 1130$

$2 \cdot 3177>0 \cdot 10$ n.s.

(e) Lake Pukaki

$0.00001<1>0.20$ n.s.

(f) Ariki Junction

$0.0269 \quad 0.4192 \quad>0.20$ n.s.

(g) Skippers Saddle

$0.0006 \quad 1 \quad>0.20$ n.s.

TABLE 7

$A$ summary of the effect of extra heterochromatin on chiasma frequency in Phaulacridium marginale. (The segments have been recorded against a $O B$ background and the $B$ 's against a $B B S_{9} B B S_{10}$ $B B S_{11}$ background)

$\begin{array}{lccccc}\text { Population } & \begin{array}{c}\text { Basic } \\ \text { karyotype }\end{array} & +1 \mathrm{~B} & +2 \mathrm{~B} & 1 \mathrm{seg} . & 2 \text { segs } \\ \text { LC } & 17 \cdot 91 & 17 \cdot 32 * & - & - & - \\ \text { SU } & 16 \cdot 37 & 17 \cdot 60 & 14.90 & - & - \\ \text { TP } & 16 \cdot 30 & 16 \cdot 05 & - & 16 \cdot 60 * & - \\ \text { AW } & 15 \cdot 19 & 15 \cdot 88 & 15 \cdot 90^{*} & - & - \\ \text { LO } & 14 \cdot 99 & - & - & 13 \cdot 00^{*} & - \\ \text { LP } & 15 \cdot 23 & - & - & 15 \cdot 70^{*} & - \\ \text { AJ } & 15 \cdot 09 & - & - & 14 \cdot 75 & - \\ \text { SS } & 15 \cdot 44 & - & - & 15 \cdot 09 & 14 \cdot 80^{*} \\ \text { AO } & 15 \cdot 30 & 14 \cdot 80 & - & 17 \cdot 00^{*} & - \\ \text { OM } & 15 \cdot 37 & 17 \cdot 30 & 16 \cdot 50 & 17 \cdot 29 & 17 \cdot 50 \\ & & * & & \end{array}$

were the polymorphisms extensive. Such populations are of interest in that only in these situations can estimates of possible synergistic action between the two types of supernumerary heterochromatin in the same species be 
TABLE 8

Chiasma scores from Omarama, 1973 (each mean and standard deviation is based on 10 cells)

$\mathrm{OB}$

(a) Means

\begin{tabular}{|c|c|c|c|}
\hline & OB & $1 \mathrm{~B}$ & 2B \\
\hline 0 segments & $15 \cdot 7,14 \cdot 7,15 \cdot 7$ & $16 \cdot 0,18 \cdot 6$ & $16 \cdot 0,15 \cdot 8,17 \cdot 7$ \\
\hline 1 segment & $\begin{array}{l}15 \cdot 8,20 \cdot 9,17 \cdot 7 \\
16 \cdot 9,15 \cdot 3,17 \cdot 6 \\
17 \cdot 7\end{array}$ & $\begin{array}{l}16 \cdot 8,16 \cdot 3,17 \cdot 7 \\
18 \cdot 7\end{array}$ & $17 \cdot 8$ \\
\hline 2 segments & $\begin{array}{l}18 \cdot 2,17 \cdot 2,17 \cdot 8 \\
16 \cdot 8\end{array}$ & $16 \cdot 0$ & 一 \\
\hline 3 segments & 一 & $16 \cdot 9$ & $17 \cdot 0$ \\
\hline \multicolumn{4}{|c|}{ (b) Log variance } \\
\hline & $\mathrm{OB}$ & $1 \mathrm{~B}$ & $2 \mathrm{~B}$ \\
\hline 0 segments & $\begin{array}{l}0.228,-0.046 \\
0.195\end{array}$ & $0 \cdot 042,0 \cdot 139$ & $0.551,-0.073$ \\
\hline 1 segment & $\begin{array}{l}0.551,0.195 \\
0.083,0.494 \\
-0.046,-0.046 \\
0.063\end{array}$ & $\begin{array}{cl}0.349, & 0.194 \\
-0.074, & 0.0462\end{array}$ & $0 \cdot 110$ \\
\hline 2 segments & $\begin{array}{l}-0.398,-0.074 \\
-0.206,0.419\end{array}$ & 0.347 & - \\
\hline 3 segments & 一 & $-0 \cdot 264$ & $0 \cdot 242$ \\
\hline
\end{tabular}

TABLE 9

Analyses of variance of the mean cell chiasma frequencies and the log variance for the OM population. (The 1972 data is from Westerman and Fontana, 1973)
Item
d.f. M.S.
V.R.
P

(a) 1973 mean Xa frequency

Between B classes

$\begin{array}{rrll}2 & 4 \cdot 234 & 1 \cdot 0 & \text { n.s. } \\ 3 & 21 \cdot 723 & 1 \cdot 483 & \text { n.s. } \\ 4 & 14 \cdot 799 & 1 \cdot 037 & \text { n.s. } \\ 17 & 14 \cdot 273 & & \end{array}$

Between segment classes

Error

(b) $1973 \log$ variances

$\begin{array}{lrrrr}\text { Between B classes } & 2 & 0.026 & 1 \cdot 0 & \text { n.s. } \\ \text { Between segment classes } & 3 & 0.058 & 1.0 & \text { n.s. } \\ \text { B } \times \text { segment interaction } & 4 & 0.061 & 1.0 & \text { n.s. } \\ \text { Error } & 17 & 0.066 & & \end{array}$

(c) $1972+1973$ means

Between B classes

Between segment classes

$3 \quad 1.240$

$\mathrm{B} \times$ segment interaction

Error

$1 \cdot 240$
$34 \cdot 524$

$1 \cdot 0$

n.s.

$\begin{array}{ll}3 & 27 \cdot 136\end{array}$

$28 \quad 13 \cdot 791$

(d) $1972+1973 \log$ variances

Between B classes

Between segment classes

$\mathrm{B} \times$ segment interaction

Error

$\begin{array}{rlll}3 & 0.017 & 1 \cdot 0 & \text { n.s. } \\ 3 & 0.037 & 1.0 & \text { n.s. } \\ 7 & 0.039 & 1.0 & \text { n.s. } \\ 28 & 0.085 & & \end{array}$


obtained. Populations TP and AO had too few individuals with B's or segments, so the analysis was confined to the data from the OM population (see Table 8). The analysis is complicated by two factors, however. Firstly, the presence of up to $2 \mathrm{~B}$ 's together with possible presence of extra segments on neither, either or both homologues of the $S_{9}, S_{10}$ and $S_{11}$ chromosomes means that there are a total of 81 karyotypes possible within the population (108 if one includes the 3B individuals observed in 1972). To date only 21 of these have been recorded. Obviously, then, small samples will not include all possible karyotypic classes. Secondly, not all karyotypic classes are equally represented-some being more frequent than others. To allow for these difficulties, the analysis of the OM population data was carried out in the form of an $\mathrm{R} \times \mathrm{C}$ table with missing cells (see Snedecor, 1956 p. 385) using a DEC system-10. The results of the analyses on means and log variances are shown in table 9, $a$ and $b$.

It would appear from this table that in the 1973 sample neither B chromosomes or segments significantly affect either metric, and neither is there any significant interaction. Since data were available from the 1972 collection at $\mathrm{OM}$ and there was no significant difference between years, the pooled 1972 and 1973 data were re-analysed. The results are shown in table 9, c and d. Again there is no significant effect of either class of extra heterochromatin alone, nor is there any significant interaction. However, in view of the large number of karyotypes possible within this population, very much larger samples are required to confirm the validity of these findings. Such a collection is now in hand.

\section{Discussion}

Phaulacridium marginale (Walker) is common throughout New Zealand in open grasslands below $1000 \mathrm{~m}$ (Bigelow, 1967). Its closest relative is the Australian species $P h$. vittatum (Sjöst) from which it is thought to be reproductively isolated. Since the grasshopper is found only at lower altitudes it has been suggested that $P h$. marginale has either survived the pleistocene glaciations in New Zealand in refugia, for example in Northland, from which it has since spread; or it has colonised New Zealand, probably from Australia, at some time during the last 10,000 years. The presence of two morphologically different types of individuals in the MacKenzie Plains area, South Island, which exist in separate populations and which differ in at least two genetical parameters (Westerman, 1974), suggests that the genus is either in the process of speciating or has speciated since this post-glacial expansion.

It has been shown that $P h$. marginale is extensively polymorphic for supernumerary heterochromatin which can be present in a cell both as $\mathrm{B}$ chromosomes and as extra segments on the smaller autosomes. Both polymorphisms occur in widely separated populations on both South and North Islands (Martin, 1970; Westerman, 1974). The multiple regression analyses suggest that the presence of both types of polymorphism in a population is significantly related to the environment. Thus in $P h$. marginale B's and segments occur with low frequency in populations having a high annual rainfall but a low July (winter) rainfall. This suggests that there are different requirements at different stages of development, as would also appear to be the case in $M$. maculatus where Robinson (1973) has shown that OB 
individuals have a higher survival value as embryos in winter but have lower fitness at other stages of the life history.

The role of the extra heterochromatin in $P h$. marginale is not immediately apparent. Certainly to date there is no significant effect of either B's or extra segments on chiasma frequency. It has been shown in both the 1972 and 1973 collections from Omarama that there is a tendency for individuals with either B's or segments to have higher mean cell chiasma frequencies than those with no extra heterochromatin. It must be emphasised, however, that only much more extensive collections will show whether or not these trends are significant. Similarly, there would appear to be no signficant interaction between the B's and segments. Thus the extra heterochromatin has similar effects whether present in the cell as a B chromosome or as an extra segment on an autosome. Such a finding is of interest in view of the possible differences in origin of the two polymorphisms in Ph. marginale.

Since the species is brachypterous with fully winged individuals occurring only rarely, it has limited powers of dispersal. In view of the width and age of Cook Straits, it could be argued that the presence of B's and segments over such large areas on both islands indicates the antiquity of these polymorphisms. Indeed, the remarkable similarity in morphology and behaviour of the B's and segments in the two closely related species Ph. vittatum and $P h$. marginale could argue for an even earlier, monophylletic origin of both types of supernumerary elements, possibly in a common ancestral species. Such an origin would be at least 10,000 to 12,000 years B.c. Similarly, Rowe and Westerman (1974) have argued that if the presence of B's in both Tasmanian and Australian mainland populations is used to indicate antiquity of origin, then B's in Ph. vittatum must be at least 10,000 years old.

Arguments for homology of genetic material in different species must, however, be viewed with some suspicion as we know that similarity in number, shape and behaviour of chromosomes, even in related species, often belies marked differences between them both in structure (John and Lewis, $1965 b$ ), and in relative amounts of DNA (John and Hewitt, 1966b). Even $\mathrm{B}$ chromosomes from widely separated populations in a single species have been shown to differ in DNA base composition (Gibson and Hewitt, 1972).

Thus, whilst an ancient monophylletic origin implying great stability and perhaps selective advantage of the supernumerary heterochromatin in $P h$. marginale is possible, other explanations are equally probable. One of these, which will adequately explain not only the widespread occurrence of both of these polymorphisms in New Zealand but also the similarity of B's and segments in $P h$. marginale and $P h$. vittatum is that $\mathrm{B}$ chromosomes arise and have arisen as a result of non-disjunction of the $\mathrm{X}$ chromosome or of the autosomes (Hewitt and John, 1970, 1971, 1972; White, 1973; Hewitt, 1973, 1974). The B chromosomes could then be of quite recent origin.

Such a possibility of recent and perhaps frequent origin of B's from $\mathrm{X}$ chromosomes and small autosomes in the Orthoptera has been discussed in detail by Hewitt $(1973,1974)$. This reasoning can be applied not only to Phaulacridium but can also be extended to include other examples from a variety of organisms.

It is known that additional copies of sex chromosomes can be tolerated in many species. Even in man, individuals with up to three extra X's are known (Chu, 1962). When extra copies of the $\mathrm{X}$ chromosome are present they are often heterochromatinised, thereby being presumably genetically in- 
activated-perhaps even in grasshoppers (see Hewitt, 1973), for refs). Initial tolerance of extra X chromosomes, and of extra autosomes, is an essential prerequisite for production of a B chromosome from this source. The ability to handle extra copies of the sex chromosomes is probably related to the fact that many species of animals from insects to mammals normally have to contend with different numbers of $\mathrm{X}$ chromosomes in the two sexes. Such species could then be regarded as being "pre-adapted" to handle extra $\mathrm{X}$ univalents. Further support for this "pre-adaptation" to tolerance of the products of non-disjunction of the sex chromosome comes from studies on $\mathrm{X}_{n} \mathrm{O}$ sex-chromosome systems (see John and Lewis, 1965a, for refs) and from selection for increased numbers of sex chromosomes in dermestid beetles (Shaw, 1968). In dermestes the normal sex-chromosome system is Xy. John and Shaw (1967) demonstrated that although Xyy individuals are meiotically stable, those with three or more y's (produced in selection experiments) were highly unstable. This compares with the meiotic stability of 2B but instability of $\geqslant 3 \mathrm{~B}$ carrying individuals of Myrmeleotettix maculatus.

Hewitt (1974), in discussing the origin of B chromosomes in Orthoptera, has shown that the recorded $B$ chromosomes of a large number of species can be categorised into two major classes (see his table 1) -those with a probable origin from the smaller autosomes and those originating from the $\mathrm{X}$ chromosome. Table 10 shows a comparison of the B and sex chromosomes in some other animal and plant species. Even in plants where few species have cytologically differentiated sex chromosomes, B chromosomes can in some cases (e.g. Rumex) be regarded as being $\mathrm{X}$-derived.

TABLE 10

A comparison of some B chromosomes with their presumed sex chromosome progenitors. (For a much more comprehensive list of Orthopteran species see Hewitt, 1974)

Species
INSECTS
Theudoria melanocnemis
Moraba viatica
Chorthippus parallelus
Phaulacridium marginale
Cimex lecticularis
MARSUPIALA
Schoinobates volans
MAMMALIA
Reithrodontomus megalotis
Vulpes fulvus
PLANTS
Rumex thysifloris

INSECTS

Beplessia Sp. 1

Atractomorpha australis Valanga irregularis Phaulacridium marginale

\section{Marsupiala \\ Echymipera kalabu}

Mammalia

Vulpes vulpes

$\overbrace{\text { Sex chromosome }}^{\text {Morphology }}$

(a) Basic $B$

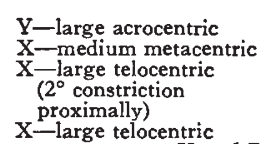

$\mathrm{x}$ - proximally) $\mathrm{X}$ and $\mathrm{B}$ indistinguishable
Acrocentric, like $Y$
Medium metacentric, like X
Large telocentric, like $\mathbf{X}$ ( $2^{\circ}$ constriction
proximally)
Large telocentric, like $\mathrm{X}$

$$
\begin{aligned}
& \mathrm{Y}-\text { small acrocentric } \\
& \mathrm{Y} \text {-small metacentric } \\
& \mathrm{Y} \text {-small acrocentric } \\
& \mathrm{X} \text { - large metacentric }
\end{aligned}
$$

(b) Derived $B^{\prime} s$

Small acrocentric like $Y$

(b) Very small acrocentric

Small acrocentric, like Y

Large metacentric, like $\mathrm{X}$

Medium metacentric isochromosome

Acrocentric, half size of $\mathrm{X}$

Telocentric, half size of $\mathrm{X}$ (a) Small metacentric, like $Y$

(a) Medium telocentric,

(b) Medium metacentric isochromosome

$\mathrm{X}$-small metacentric
Small metacentric half size of $\mathbf{Y}$. Subject to similar elimination as sex chromosomes

Small metacentric, like $Y$
Reference

\author{
White et al., 1967 \\ Westerman (unpublished) \\ Westerman (this paper) \\ Darlington, 1939 \\ Hayman and Martin, 1965 \\ Shellhammer, 1969 \\ Gustavsson and Sundt, 1965 \\ Zük, 1969
}

Westerman (unpublished)

White, 1973

Westerman (unpublished)

Westerman (this paper)

Hayman et al., 1969

Buckton and Cunningham, 1971 
The probable first step then in the evolution of some B chromosomes is the non-disjunction of an $\mathrm{X}$ and the survival of the products of non-disjunction. In the course of the present population studies on the genus Phaulacridium occasional males of both $P h$. marginale and $P h$. vittatum have been encountered in which some germ line cells contained two $\mathrm{X}$ chromosomes. These two X's, though fully homologous, were never seen to form chiasmata and occasionally moved to the same pole. This failure to form chiasmata of two or more fully homologous $\mathrm{X}$ chromosomes in males of normally $\mathrm{XO}$ species is true not only of naturally occurring polysomic and polyploid cells (e.g. White, 1933, 1970; Lewis and John, 1959; John and Henderson, 1962; Martin, 1970) but also of X-ray induced X polysomics (Westerman, 1968). In similar manner multiple $\mathrm{X}^{\prime} \mathrm{s}$ in $\mathrm{X}_{n} \mathrm{O}$ male spiders (Revell, 1947) and Stone flies (Matthey and Aubert, 1947) or in $\mathrm{X}_{n} \mathrm{Y}$ cyprid Ostracods (Dietz, 1955, 1958) and Cimex (Darlington, 1939) never form chiasmata. They usually lie side by side, sometimes have interconnecting fibrils and show persistent heterochromatic association which may subsequently lapse at or before MI (e.g. Tegenaria, Revell, loc. cit.) or be maintained until interkinesis, thus ensuring that all X's move en bloc to the same pole.

Similar patterns of behaviour have been reported for X-B associations (and even B-B). The non-chiasmate nature of these $\mathrm{X}-\mathrm{B}$ associations has often been inferred to prove non-homology of the elements. As with the $\mathrm{X}-\mathrm{X}$ associations above, the parallel orientation of heterochromatic $\mathrm{X}$ and $\mathrm{B}$ chromosomes may involve interconnecting fibrils (plate II, a) and may persist until MI (Rowe and Westerman, 1974) or until much later, giving distortional segregation (Jackson and Cheung, 1967; Fontana and Vickery, 1973).

Non-disjunction of the $\mathrm{X}$ chromosome does occur then in the genus Phaulacridium and these extra X's in normally XO males show no chiasmate pairing with the original $\mathrm{X}$ and may appear to be slightly heterochromatic. Thus the products of non-disjunction already have two of the " properties" of a B chromosome (see Battaglia, 1964). Subsequent " evolution" into a $\mathrm{B}$ chromosome may then entail loss of genetic material, probably most often from the distal end of the chromosome. In this context it should be noted that not all of the genetic information contained in the " $\mathrm{X}$ " is essential in some species and may get lost, giving polymorphism for different sized X's as in Mus musculoides (Matthey, 1967). Such a distal loss of material from an X-like progenitor seems to have occurred in the B of Myrmeleotettix maculatus (Gallagher et al., 1973) and may also explain the presence of the small telocentric B chromosome in Ph. marginale. Subsequent misdivision of the centromere would lead to a metacentric isochromosome of the type seen in the OM population. Other possible steps in the evolution of a $\mathrm{B}$ chromosome are possible inversion or centric shift within the isochromosome as seen in $M$. maculatus (John and Hewitt, 1965a) and build up of highly repeated sequences to give "satellite" DNA (Gibson and Hewitt, 1972). One or all of these may occur in any given species and any of them would almost inevitably lead to the isolation of the B from its "parent" X chromosome.

If such a sequence of events has occurred in the genus Phaulacridium then since the $\mathrm{X}$ chromosomes of $P h$. vittatum and $P$ h. marginale are morphologically similar perhaps it is not altogether surprising that their "Basic-type" B chromosomes (long telocentric) should also look similar. Indeed, the 
similar genetic content of the original X's in the two species would also presumably lead to somewhat similar behaviour patterns of the B's and to their similar roles in different populations. Since the background genotype in which these originally similar X's have evolved and the genotypeenvironmental interactions will differ in different populations, then it is reasonable to expect (presumed identical) B chromosomes in widely separated populations to behave differently, as is the case in $M$. maculatus (Hewitt, 1973, 1974). Such arguments could explain the differences in AI segregation of $\mathrm{B}$ chromosomes of mainland and a Tasmanian population of $P h$. vittatum - these populations having been separated for at least 10,000 years (Rowe and Westerman, 1974).

Further evidence of a probable origin of some B's from X chromosomes comes from the many experiments on interchromosomal effects on recombination and radiation resistance/sensitivity in Drosophila melanogaster. In this species it is known that the $\mathrm{X}$ chromosome carries polygenes which control not only the amount of recombination in chromosomes 2 and 3 (Schultz and Redfield, 1951; Suzuki, 1963; Hinton, 1967) but also increased resistance/ sensitivity to high doses of $y$-rays (Westerman, J. M., unpublished). These two processes of repair and recombination require similar if not identical enzyme systems (see Westerman, 1972, for refs). If Orthopteran X chromosomes carry similar polygenes, then the known influence of $\mathrm{B}$ chromosomes on chiasma formation (John and Hewitt, 1965a,b) is perhaps to be expected. Similarly, since the autosomes too carry genes controlling repair/recombination, the known effect on gene recombination and production of mitotic damage in both animals and plants of B chromosomes derived from them (Ehrendorfer, 1959; Rhoades, 1968; Ward, 1973) is also to be expected. It seems possible then that B chromosomes in Phaulacridium species may have separate and perhaps recent origin from the $\mathrm{X}$, as is the case in $M$. maculatus from Britain and Scandinavia.

What then of the supernumerary segments in $P h$. marginale? As with the $\mathrm{B}$ chromosomes, it is possible to argue for an ancient origin for these, particularly for the segment making up the short arm of the $S_{11}$. White (1973) notes that " no group (of animals) seems to be known in which polymorphisms for extra segments exist without simultaneous presence of supernumerary chromosomes either in the same or in closely related species". It has been suggested that terminal supernumerary segments have most likely arisen by translocation between two non-homologous chromosomes" one of which in some instances may have been a heterochromatic supernumerary chromosome" (White, loc. cit.). Although such a mode of origin is possible, both direct and indirect evidence argues against it. Southern (1967) has described the only known case of the translocation of a B fragment on to an autosome in an animal, in this case a long chromosome in $M$. maculatus, and he states that the products of this translocation are unstable. Translocation between heterochromatic and euchromatic regions is also argued to be a rare event in male Acridids by Westerman (1968).

An alternative explanation of the origin of supernumerary segments in Phaulacridium, as in many grasshoppers, is that they have arisen independently many times by direct duplication of chromosome regions (Shaw, 1971; White, 1973), or by the rapid accumulation of highly repeated sequences. In this context it should be noted that in many grasshoppers supernumerary segments are frequently located at the distal end of the shorter autosomes- 
precisely those regions which have wide G-bands (Fox et al., 1973; Hewitt, 1973).

Acknowledgments.-This work was made possible by a Research Grant (D72/15255) awarded by the A.R.G.C. I would like to thank $\mathrm{Dr}$ and Mrs C. T. Cowell for their help in collecting the material and Dr G. M. Hewitt for reading the manuscript.

\section{REFERENCES}

Battaglia, E. 1964. Cytogenetics of B-chromosomes. Caryologia, 17, 245-299.

BIGELOW, R. s. 1967. The Grasshoppers (Acrididae) of New Zealand. University of Canterbury Publications: No. 9, Christchurch, New Zealand.

BUCKTON, K. E., AND CUNNingham, c. 1971. Variations of the chromosome numbers in the Red Fox (Vulpes vulpes). Chromosoma (Berl.), 33, 268-272.

CHU, Е. н. у. 1962. Abnormalities of sex chromosomes. In Mammalian Cytogenetics and Related Problems in Radiobiology, pp. 209-232. Pergamon Press, Oxford.

DARLINGTON, C. D. 1939. The genetical and mechanical properties of the sex chromosomes. V. Cimex and the Heteroptera. 7. Genetics, 39, 101-137.

DIETZ, R. 1955. Zahl und Verhalten der Chromosomen einiger Ostracoden. Naturforsch., $10 b, 92-95$.

DIETZ, R. 1958. Multiple Geschlechtschromosomen bei den Cypriden Ostracoden, ihre Evolution und i-t Teilungsverhalten. Chromosoma (Berl.), 9, 359-440.

EHRENDORFER, E. 1959. Spontane Chromosomen aberrationen und andere Meiosestorungen bei diploiden sippen des Achillea millifolium-Komplexes. Chromosoma (Berl.), 10, 365-406.

PONTANA, P. G., AND viCKeRY, v. R. 1973. Segregation distortion in the B-chromosome system of Tettigidea lateralis (Say)(Orthoptera: Tettrigidia). Chromosoma (Berl.), 43, 75-100.

FOX, D. P., CARTER, K. C., AND HEWITT, G. M. 1973. Giemsa banding and chiasma distribution in the Desert Locust. Heredity, 31, 272-276.

GALLAGHER, A., HEWITT, G. M., AND GIBSON, I. 1973. Differential Giemsa staining of heterochromatic B-chromosomes in Myrmeleotettix maculatus (Thunb.) (Orthoptera: Acrididae). Chromosoma (Berl.), 40, 167-172.

GIBSON, I., AND HEWITT, G. M. 1972. Interpopulation variation in the satellite DNA from grasshoppers with B-chromosomes. Chromosoma (Berl.), 38, 121-138.

GUSTAVsson, I., AND SUNDT, c. o. 1965. Chromosome complex of the family Canidae. Hereditas, 54, 249-254.

HAYMAN, D. L., AND MARTIN, P. G. 1965. Supernumerary chromosomes in the marsupial Schoinobates volans (Kerr). Aust. F. Biol. Sci., 18, 1081-1082.

haYman, D. L., MARTIN, P. G., AND WALLER, P. F. 1969. Parallel mosaicism of supernumerary chromosomes and sex chromosomes in Echymipera kalabu (Marsupiala). Chromosoma (Berl.), 27, 371-380.

HEWITT, G. M. 1973. On the evolution and maintenance of B-chromosomes with particular reference to Orthopteran systems. In Chromosomes Today, 4.

HEWITT, G. M. 1974. The integration of supernumerary chromosomes into the Orthopteran genome. In Cold Spring Harbor Symp. Quant. Biol.

HEWITT, G. M., AND JOHN, B. 1967. The B-chromosome system of Myrmeleotettix maculatus (Thunb.). III. The statistics. Chromosoma (Berl.), 21, 140-162.

HEWITT, G. M., AND JOHN, B. 1968. Parallel polymorphism for supernumerary segments in Chorthippus parallelus (Zetterstedt.). I. British Populations. Chromosoma (Berl.), 25, 319-342.

HEWITT, G. M., AND JOHN, B. 1970. The B-chromosome system of Myrmeleottix maculatus (Thunb.). IV. The dynamics. Evolution, 24, 169-180.

HEWITT, G. M., AND JOHN, B. 1971. The cytogenetic systems of grasshoppers and locusts. I. Chortoicetes terminifera. Chromosoma (Berl.), 34, 302-323.

HEWITT, G. M., AND JOHN, B. 1972. Interpopulation sex chromosome polymorphism in the grasshopper Podisma pedestris. II. Population parameters. Chromosoma (Berl.), 37, 23-42.

HEWITT, G. M., AND RUSCOE, C. 1971. Changes in microclimate correlated with a cline for B-chromosomes in the grasshopper Myrmeleotettix maculatus (Thunb.). (Orthoptera: Acrididae.) 7. Anim. Ecol., 40, 753-765. 
HewitT, G. M., AND SGHroeter, G. 1969. Population cytology of Oedaleonotus. I. The karyotypic facies of Oedaleonotus enigma (Scudder). Chromosoma. (Berl.), 25, 121-140.

Hinton, c. w. 1967. Genetic modifiers of recombination in Drosophila melanogaster. Can. $\mathcal{F}$. Genet. Cytol., 9, $711-716$.

JACKSON, w. D., AND CHEUnG, D. s. M. 1967. Distortional meiotic segregation of a supernumerary chromosome producing differential frequencies in the sexes in the shortthorned grasshopper Phaulacridium vittatum. Chromosoma (Berl.), 23, 24-37.

JOHN, B., AND fReEMAN, M. G. ST. C. 1974. B-chromosome behaviour in Phaulacridium vittatum. Chromosoma (in press).

JOHN, B., AND hENDERSON, s. A. 1962. Asynapsis and polyploidy in Schistocerca paranensis. Chromosoma (Berl.), 13, 111-147 (1962).

JOHN, B., AND HEWITT, G. M. 1965a. The B-chromosome system of Myrmeleotettix maculatus. I. The mechanics. Chromosoma (Berl.), 16, 548-578.

JOHN, B., AND HEWITT, G. M. 1965b. The B-chromosome system of Myrmeleotettix maculatus. II. The statics. Chromosoma (Berl.), 121-138.

JOHN, B., AND HEWTTT, G. M. 1966. Karyotype stability and DNA variability in the Acrididae. Chromosoma (Berl.), 20, 155-172.

JOHN, B., AND Lewis, K. R. 1965a. The Meiotic System. Protoplasmatologia VI fl. SpringerVerlag, Vienna and New York.

JOHN, B., AND LEWIS, K. R. 1965b. Genetic speciation in the grasshopper Eyprepocnemis plorans. Chromosoma (Berl.), 16, 308-344.

JOHN, B., AND SHAW, D. D. 1967. Karyotypic variation in Dermestid beetles. Chromosoma (Berl.), 20, 317-385.

JONES, R. N., AND REES, H. 1967. Genotypic control of chromosome behaviour in Rye. XI. The influence of B-chromosomes on meiosis. Heredity, 22, 333-347.

LEWIS, K. R., AND JOHN, B. 1959. Breakdown and restoration of chromosome stability following inbreeding in a locust. Chromosoma (Berl.), 10, 589-618.

martin, J. M. 1970. The cytogenetics of some New Zealand grasshoppers (Acrididae). M.Sc. Thesis, Victoria University of Wellington.

MatThey, R. 1967. Étude de deux femelles hétérozygotes pour une délètion partielle portant sur un bras du chromosome-X chez Mus (Leggada) minutoides musculoides (Temm). Cytogenetics, 6, 168-177.

matthey, R., AND Aubert, J. 1947. Les chromosomes des Plécoptères. Bull. Biol., 81, 202-246.

NUR, U. 1961. Meiotic behaviour of an unequal bivalent in the grasshopper Calliptamus palaestinensis (BdHr). Chromosoma (Berl.), 12, 272-279.

NUR, U. 1969. Mitotic instability leading to an accumulation of B-chromosomes in grasshoppers. Chromosoma (Berl.), 27, 1-19.

PUTEYEVSKY, E., AND ZOHARY, D. 1970. Behaviour and transmission of in diploid Dactylis glomerata. Chromosoma (Berl.), 32, 135-141.

ReVelL, s. 1947. Controlled X-segregation at meiosis in Tegenaria. Heredity, 1, 337-347.

RHOADES, M. M. 1968. Studies in the cytological basis of crossing-over. In Replication and Recombination of Genetic Material (W. J. Peacock and R. D. Brock, eds), pp. 229-241. Australian Academy of Science.

ROBrnson, P. M. 1973. Ecological studies of B-chromosomes in Myrmeleotettix maculatus (Thunb.). Ph.D. Thesis. University of East Anglia.

roWe, H. J., AND Westerman, M. 1974. Population cytology of the genus Phaulacridium. I. Phaulacridium vittatum (Sjost)-Australian mainland populations. Chromosoma (in press).

SCHULTZ, J., AND REDFIELD, $\mathrm{H}$. 1951. Interchromosomal effects on crossing over in Drosophila. Cold Spring Harbor Symp. Quant. Biol., 16, 175-197.

SHAW, D. D. 1968. Selection for supernumerary Y-chromosomes in Dermestes maculatus (Coleoptera: Dermestidae). Can. F. Genet. Cytol., 10, 54-62.

SHAW, D. D. 1971. The supernumerary segment system of Stethophyma. II. Heterochromatin polymorphism and chiasma variation. Chromosoma (Berl.), 34, 19-39.

SHELlHAMMER, H. s. 1969. Supernumerary chromosomes of the harvest mouse, Reithrodontomys megalotis. Chromosoma (Berl.), 27, 102-108.

SNEDeCor, G. W. 1956. Statistical Methods, 5th ed. Ames, Iowa State University Press.

SOUTHERN, D. I. 1967. Fragment chromosomes in Myrmeleotettix maculatus (Thunb.). Chromosoma (Berl.), 22, 227-240.

suzuKr, D. 1963. Interchromosomal effects on crossing over in Drosophila melanogaster. II. A re-examination of X-chromosome inversion effects. Genetics, 48, 1605-1617. 
WARD, E. J 1973. The heterochromatic B-chromosome of Maize: The segments affecting recombination. Chromosoma (Berl.), 43, 177-186.

Westerman, M. 1968. The effect of X-irradiation on male meiosis in Schistocerca gregaria (Forskal). II. The induction of chromosome mutations. Chromosoma (Berl.), 24, 17-36.

Westerman, M. 1969. Parallel polymorphism for supernumerary segments in Chorthippus parallelus (Zetterstedt). II. French populations. Chromosoma (Berl.), 26, 7-21.

westerman, m. 1970. Parallel polymorphism for supernumerary segments in Chorthippus parallelus. V. A new polymorphism in Europe. Heredity, 25, 662-667.

WESTERMAN, M. 1972. Dose-response of chiasma frequency to X-irradiation in Chorthippus brunneus. Mutation Res., 15, 55-65.

Westerman, M. 1974. Population cytology of the genus Phaulacridium. II. Phaulacridium marginale (Walker) - Chiasma frequency studies from South Island, N.Z. Chromosoma (Berl.)(in press).

WESTERMAN, M., AND FONTANA, P. G. 1973. Polymorphisms for extra heterochromatin in Phaulacridium marginale. Heredity, 31, 223-229.

white, м. J. D. 1933. Tetraploid spermatocytes in a locust, Schistocerca gregaria. Cytologia, $5,135-139$.

WHITE, M. J. D. 1970. Asymmetry of heteropyenosis in tetraploid cells of a grasshopper. Chromosoma (Berl.), 30, 51-61.

whrTe, м. J. D. 1973. Animal Cytology and Evolution, 3rd ed. Cambridge University Press, Cambridge.

WHITE, M. J. D., CARSON, H. L., AND CHENEY, J. 1964. Chromosomal races in Australian grasshopper Moraba viatica in a zone of geographical overlap. Evolution, 18, 417-429.

WHITE, M. J. D., MESA, A., AND MESA, R. 1967. Neo-XY sex chromosome mechanisms in two species of Tettigonioidea (Orthoptera). Cytologia, 32, 190-199.

ZARCHI, Y., SIMCHEN, G., HILLEL, J., AND SHAAP, T. 1972. Chiasmata and the breeding system in wild populations of diploid wheats. Chromosoma (Berl.), 38, 77-94.

ZÉCÉVIČ, L., AND PAUNOVIČ, D. 1969. The effect of B-chromosomes on chiasma frequency in wild populations of rye. Chromosoma (Berl.), 27, 198-200.

zük, J. 1969. The additional heterochromatic chromosome and its influence on sex chromosome pairing in Rumex. Heredity, 24, 69-74. 